\title{
Complexities in Ethical Decision-Making
}

\author{
Libby V. Morris ${ }^{1}$ \\ Published online: 25 January 2019 \\ (C) Springer Nature B.V. 2019
}

The wave of scandals across education, corporate, and governmental sectors over the past few years drives home the need for greater attention to ethical decision-making and ethical behavior. Ann E. Tenbrunsel, the Rex and Alice A. Martin Professor of Business Ethics at the University of Notre Dame, clearly made this point as the signature guest lecturer during the University of Georgia's 2018 Ethics Week. Okay, you are probably laughing now....a week for ethics! Please note that this week is our intentional focus on ethics, not the sole week we have set aside to "be ethical."

Professor Tenbrunsel began by stating that we, like other people, are generally not as ethical as we think we are. Some shifting in the seats occurred as this point because most academics and students like to think of themselves as principled and dedicated to high standards of conduct. Yet, through multiple examples, we were led to see that a gap exists between who we think we are, who we would like to be, and who we actually are. Her research into behavioral ethics investigates the effects of ethical boundaries and ethical awareness on decision-making. Our blind spots do not allow us to see our behaviors or decisions as having ethical components.

For example, according to Professor Tenbrunsel, if we are asked to predict a behavior, we think abstractly and big picture; and we tend to project acting in highly ethical, desirable ways. Yet, at the time of a decision, we tend to think concretely with specificity; and we bring other frameworks into play. Thus, the ethical dimensions of a decision may fade as other issues (e.g., profitability, winning, pleasing a superior) ascend. "Bounded awareness" allows us to exclude relevant information when we define a problem and thus limits the full examination of ethical dimensions. It was informative to learn that we easily make prediction errors about how we will behave in the prediction-action-recollection phases of decision-making and that subsequently we may participate in revisionary retrospectives on our actions. Context, other criteria, and decision frames allow us to compartmentalize our decisions. And, we may even recast our less than optimal decisions with softening euphemisms, such as "we are just greasing the wheels" as opposed to "tipping the scales."

My take-away was that "good" people often make poor decisions and may engage unintentionally in unethical behaviors as a result of bounded awareness, ethical fading, and

Libby V. Morris

lvmorris@uga.edu 
poorly designed organizational systems that compromise ethical behavior. In Blind Spots: Why we fail to do what's right and what to do about it (Bazerman \& Tenbrunsel, 2011), Tenbrunsel and co-author Max H. Bazerman shared their research on bounded ethicality and the emerging field of behavioral ethics, that is, what do people actually do when facing ethical dilemmas.

Ethical lapses and unethical behaviors are not only concerns for individuals, but also for organizations because groupthink and pressures of conformity may pervade decision-making and actions across levels and individuals. In the corporate world the failures at Enron, Big Tobacco, and the Madoff financial empire are textbook cases of ethical behaviors ignored and corruption writ large. In post-secondary education we have our own examples of unethical and illegal behavior, as was recently revealed by the widely publicized Nassar case at Michigan State University. Dr. Nassar was found guilty of sexual abuse of young women gymnasts over many years. Other higher education reports tell the stories of senior administrators who have "stepped down" due to failures in financial oversight, inappropriate relationships, and other inappropriate conduct. However, ethical decision-making is required not only at the presidential and senior leadership levels; every day faculty members must make multiple decisions about people, processes, and professional and personal goals in the complex arenas of instruction and research.

In instruction faculty members must evaluate and assign grades for activities, tests, and courses overall. By compartmentalizing instructional decisions to the "objective" selection of content, instructional processes, and grading, faculty members can easily ignore, consciously or subconsciously, how instructional decisions might influence other personally important issues: instructor ratings on end-of-course evaluations, tenure and promotion decisions, future academic employment, merit raises, and teaching awards. How are instruction and providing feedback to students affected by an instructor's professional goals? How do we make explicit the ethical dilemmas surrounding what appear to be the normal day-to-day activities of teaching and learning?

In graduate education faculty-student mentoring relationships are key to career progression and outcomes; and in many areas a small number of experts in a department or discipline may be the gatekeepers for research collaborations, opportunities for instructional experience, joint publications, and future employment. This powerful control of rewards and opportunities exacerbates power differentials and sets the stage for ethical lapses by faculty members and potential moral disengagement. The \#metoo movement has brought to public attention the lasting damage from inappropriate sexual relationships between superiors and subordinates, both within and outside of the academy. In graduate education, additional issues that influence lives and careers include access to assistantships, scholarships, research, and future jobs. Taking time to individually and collectively consider the ethical dimensions of our instructional and research decisions should benefit both students and faculty.

Collectively, we do not have to begin a search for unethical people or unethical behaviors on our campuses; we need only to look at our own interactions with people and processes and our own professional aspirations and activities to see decision-points and ethical considerations that are close at hand. By reflecting on past behaviors and "routine" almost reflexive decisions made personally and within our departments, we may establish the examination of ethical implications as a priority in decisions, thereby breaking down compartmentalization, and potentially achieving the standard of "who we want to be." I highly recommend the Blind 
Spots book, and I look forward to the results and findings arising from your research into ethical issues in post-secondary higher education.

Publisher's Note Springer Nature remains neutral with regard to jurisdictional claims in published maps and institutional affiliations.

\section{Reference}

Bazerman, M. H., \& Tenbrunsel, A. E. (2011). Blind spots: Why we fail to do what's right and what to do about it. Princeton, NJ: Princeton University Press. 